\title{
Knowledge Management for Service Innovation: A Study of Sri Lankan Business Service Organizations
}

\author{
K A S K Kariyapperuma
}

\begin{abstract}
The world is moving fast from a production-based economy towards a knowledge-based one. As a result, organizations are becoming more knowledgeintensive and are increasingly dependent on innovative knowledge to create value. Therefore, the question of how activities should be organized in order to generate and exploit new forms of knowledge is very important. The main objective of this research is to explore practice-based innovation (or how this is done) in service sector organizations. Building on qualitative data from five business service sectors, the analysis identified three work activities through which knowledge for innovation is generated, showed how they constitute a common ground for knowledge creation and redefined practice as a coherent frame for these activities. The three work activities are routine designing activities, participating in the whole flow of designing, using and reflecting in action. Further, the study explains how conventional organizing destroys this knowledge. In addition to the main findings, this research identified the key factors that influence knowledge management and innovation in Sri Lankan service sector organizations. Of clear importance are strong internal linkages, open and less hierarchical structural elements, an open and positive organizational culture, strong knowledge dissemination, the availability of an expert and skilled work force, carrying out internal R\&D, technological exploration, internal systems and processes. The study makes both an empirical contribution to the emerging work on service innovation on the basis of knowledge intensiveness, and by extending a theory grounded in the existence and role of practice-based knowledge.
\end{abstract}

Keywords: knowledge intensiveness, knowledge management practices, service innovation

K A S K Kariyapperuma is a Senior Lecturer, Department of Business Administration, Faculty of Management Studies, University of Sri Jayewardenepura. E-mail: seshikakariyapperuma@yahoo.com 


\section{NSBM Journal of Management}

Vol. 1, No. 2, July-December, 2015

\section{Introduction}

Today service organisations offer tremendous potential for growth and profitability in the global economy. Service industries have expanded rapidly in the recent decades and comprise more than $70 \%$ of the gross domestic product (GDP) of all developed nations (OECD 2014).

In fact, in advanced economies services account for about two thirds of employment (OECD 2014). In the Sri Lankan context, in terms of value added, manufacturing has remained roughly constant at 31 percent of GDP, while the value addition of agriculture has declined to 10.5 percent with the service sector having a share of 58.5 of GDP (Central Bank Report 2014) indicating that the growth of the service sector is likely to continue. Even economies with a strong focus on manufacturing are shifting to service-oriented societies (Meffet \& Bruhn 2009). Now services have become the source of sustainable and strategic competitive advantage rather than competition on the basis of physical products.

It is believed that organizations must constantly develop new services to be able to compete in changing environments and thus achieve performance which requires innovation. (Teece, 2007, Popelpub 2011). Further, service organizations require service innovation for sustained growth, for raising the quality and productivity levels of services, responding to changing customer needs and expectations, or standing up to superior competitive service offerings (Miles 2005, Das et al. 2006, Spohers et al. 2008, Consoli 2009, Consoli \& Elche-Hortelano 2010,). They face a principal challenge: to '...offer the marketplace continuously improved, if not new, services' (Bullinger et al. 2003 ). Service innovations are value propositions not previously available to the customer and result from changes made to the service concept and the delivery process.

However, the status of innovation in both the service and manufacturing sectors in Sri Lanka at the moment is generally considered weak even by the standards of a developing country (Vitharana 2011). Making a presentation at the recently held 18th annual general meeting of the National Chamber of Exporters of Sri Lanka, Kelegama (2012) mentioned that the country's export performance relating to both the industrial and service sectors since 2000 has not been 'satisfactory' due to lack of innovation and limited markets. The poor state of innovation is reflected in all the innovation indexes prepared by different world national forums. In the Global Innovation Index, in 2014, Sri Lanka ranks 105th, down from 98th place in 2013 and 94th place in 2012; it is continuously declining. Its drop in the ranking is the result of the relatively poor performance of innovation on the input side where it came in at 125th place in 2014 among 142 countries. .One of the key findings of this report 
Knowledge Management for Service Innovation: A Study of Sri Lankan Business Service Organizations

(Global Innovation Index - GII, 2014) was that all the top ranking countries in the GII have invested comparatively higher amounts of resources to develop service sector innovation capabilities. Countries such as Singapore, Finland and the Netherlands that have proactively built innovative capability for the service sector have prospered.

In contrast, the limited focus on innovative capability constrained the progress of countries such as Sri Lanka and Greece (Innovative Input Index, Sri Lanka, 125th). The poor state of innovation is reflected in the very fact that it took sixty years since independence in 1948 for a national policy on innovation to be adopted in May 2009. The history of attempting to design and adopt a national innovation policy dates back to the 1960s and the final outcome related only to science and technology. Service innovation was merely seen as a subset of technological innovation or similar to innovation in manufacturing. The role of innovation in the service sector has been underappreciated.

For the above reasons, policy makers and business leaders alike now have a tendency to promote growth in the service sector in Sri Lanka. However, insufficient understanding of service management, especially in service innovation that is believed to be the new engine of economic growth in sectors such as financial, hospitality and Information and Communication Technology (ICT), may reduce the enormous benefits that can be gained from the service sector. It will hamper the growth of the Sri Lankan economy.

\section{Research Problem}

Successful service innovation requires the integration of the organization's resources and bundles of capabilities to meet customer needs. They involve understanding how the complex processes of designing services interact with the complex processes of using services (Leonard-Barton 1995). Knowledge of designing new services and using services is ambiguous since technologists often cannot say how different service designs might work without trying them out while customers cannot say what they need without trying the service either. To help this ambiguous knowledge for designing new services to surface, researchers have developed techniques for services that rely on hands-on interaction between innovators and potential customers, such as the early release of new software so that users can discover limits (Ianseti 1998) and teams can visit customers (Dougherty 1992).

Service organizations face two specific challenges when it comes to the ambiguous knowledge of designing and using service innovations surfacing. Both challenges arise from the intangible, heterogeneous, simultaneous, relational and continuous nature of services 


\section{NSBM Journal of Management}

Vol. 1, No. 2, July-December, 2015

(Yakura 2001). The first is determining what should be organized in the first place to generate new knowledge for designing new services. This is deeply and continuously intermeshed with using services, so one cannot simply organize separate venture teams, and one cannot ignore the intermeshing once the service is produced to specifications. Knowledge for new services literally exists in 'daily operations' (Itami 1987), or in the practice, which implies that services must organize everything to capture the necessary knowledge. To overcome this challenge, it is necessary to identify the kinds of activities that are most crucial to the production and capture of designing and using knowledge.

The second special challenge for service innovation is strategic. While all innovations should be framed strategically, innovation in services is more deeply intermeshed with strategy. Competitive and market pressures are forcing many service firms to provide a 'complete solution' or a more complex, end-to-end package of activities (Meyer \& DeTore 2001). According to Dankbaar (2003), service innovation concerns introducing order from a strategic perspective since allowing every client encounter to be unique produces only variation, not innovation. Services must be deployed systematically across clients to ensure quality, keep costs down and absorb new knowledge from particular applications so that the offerings can be continuously enhanced in the face of strong competition (Lowendahl 2000).

Thus, to generate and exploit knowledge for innovation, service firms must organize their work to capture the horizontal flow of designing and using, as well as the vertical flow of strategic focus and unique deployment. This study was based on the literature which considers work as practice because researchers have found that a significant amount of knowledge for service innovation is embedded in the actual practice of innovation. The practice perspective provides a view of work that fits services, but differs significantly from more established views. The traditional view conceptualizes work as a static slice of specialized labour and jobs as pre-defined activities to be executed without ambiguity. These views overlook the continuous flows of activities that comprise work by focusing on outcomes rather than on the activities through which people produce those outcomes. The traditional view of work also emphasizes the knowledge that exists in routines or expertise, and do not address the kind of knowledge that is continuously generated in practice. The literature on practice is also incomplete, which is why more theories are necessary. The current literature is based on a limited view of practice, does not connect practice to managerial issues of innovation and competitive advantage, and does not address how to organize practice for strategic ends. 
Knowledge Management for Service Innovation: A Study of Sri Lankan Business Service Organizations

Thus, the present study explores how work in service organizations can be organized to capture and exploit the knowledge that is necessary to create new services. In addition, under the broad area of knowledge management it is expected to explain why conventional organizing operates as an anti-practice strategy that eliminates the common ground and delegitimates the continued articulation of practice. Finally, the researcher tries to identify other internal factors that influence practice-based knowledge management and its influence on service innovation in the Sri Lankan context. The result of this study can be tested, elaborated and corrected in subsequent research, providing a pathway for advancing the theory of practice-based knowledge management for service innovation.

\section{Literature Review}

At the outset, the core concepts of services and service innovations are defined and described. This is followed by a narration factors affecting service innovation and thereafter aspects of capturing practice-based knowledge for innovations in business services.

\section{Services}

The literature provides a wide variety of definitions for "services". One of the earliest attempts to codify services was to define what services are not. For example, Quinn and Gagnon (1986) defined services as those economic activities in which the primary output is neither a product nor a construction. While some definitions highlight services as an activity or performance in order to solve a specific issue of the customer (e.g. Kotler 1999) others describe services as a bundle of competencies that have to be delivered (e.g. Gadrey et al. 1995). More recent literature emphasizes the interaction of service customers and service producers (Gronroos 2007). According to these definitions, the goal of a service is to provide a solution to a customer problem while making use of human-centred competencies and capabilities. However, this solution only transfers the customers' perception of reality; the outcome does not result in actual ownership. Furthermore, during the service delivery process, cooperation between client and provider plays an essential role and influences the customer's perception. Based on these foundations, and in line with Hertog et al. (2010), services can be defined as an experience or a solution for the specific issue of a customer. This definition includes all the elements of services that innovation can include and therefore is applicable to the whole service industry. This is relevant in the context of the present study 


\section{NSBM Journal of Management}

Vol. 1, No. 2, July-December, 2015

\section{Service Innovation}

Service innovation is an activity that incorporates ideas and knowledge into new or existing services to satisfy customer demands (De Jong \& Vermeulen 2003). As defined by Eurostat (1995), innovation in the services sector comprises new services as well as significant changes in services or their production or delivery. It concerns both the introduction of new services (proposed to firms or to individuals) and the reconfiguration or improvement of existing services (Miles 2005). Service innovation is different from product innovation because of the characteristics of service -intangibility, heterogeneity, perishability, and inseparability (IHIP) (Zeithaml, Parasuraman \& Berry 1990).

This unique nature of services means that service innovation may be very different from product innovation. For instance, interaction with the customer in the service development process makes the development of a new service far more complex than the development of a new tangible product (Johne \& Storey 1998). Due to its intangible nature, the development of a new service usually takes significantly less time (Griffin 1997) and requires fewer investments in physical assets. But they are less protected from direct imitation by competitors (Terrill \& Middlebrooks 1996).

They are usually interactive (client-intensive) whereby high levels of contact occur between service supplier and client in the service activity (Miles 2005). Innovation occurs as a result of such interactivity, which often means that service products are customized to the client's specific needs.

\section{Factors Affecting Service Innovation}

Researchers studying what factors determine or influence innovation (Damanpour 2001, Wolfe, 2004, Tidd et al. 2005) suggested the individual factor, the organizational factor, and the contextual factor. Kwon and Mud (2007) classified variables affecting technology adoption into individual, task-related, innovation-related, organizational, and environmental characteristics. Tornatzky and Fleischer (2006) suggested that the adoption and implementation of technological and administrative innovation would be affected by the technological context, organizational context, and the external environmental context. Scupola (2003) used technological, organizational, and environmental characteristics to explain innovations in the service sector. 
Knowledge Management for Service Innovation: A Study of Sri Lankan Business Service Organizations

\section{Capturing Practice-based Knowledge for Innovations in Business Services}

\section{Practices}

Practice is not simply about tacit knowledge, expertise or experience, but is rather about the artful, skilled combination of these along with knowledge of routines, procedures and equipment in the situation (Dougherty 2004). For example, experience affects people's ability to comprehend insights generated in practice. It would be useful to explore the kinds of experience that may enable or disenable practice-based knowledge in the business world of services (Carlile 2005).

\section{The Practice-based Perspective of Knowledge}

The concept of practice as epistemology interconnects multiple perspectives and negotiations, addressing the link between knowledge and practice, and practice as the generative source of knowledge for innovation. The practice lens is an 'original and distinctive critique of the modernist conceptions of knowledge' (Gherardi 2009, p. 115). '....It has a constructive ontology and disagrees with cognitivism and rationalism because it defines knowledge as a practical and situated activity, rather than as a "transcendental account of a decontextualized reality" (Gherardi 2009, p. 124). Knowing is not separated from doing and the practicebased perspective connects both. According to this perspective, knowledge is the situated product of work practices. Based on this, Lave (1988, pp. 180-181) defined knowledge as 'a situated knowing constituted by a person acting in a particular setting and engaging aspects of the self, the body, and the physical and social worlds'. Therefore, the work of creating knowledge for strategies and innovation is a practice that is situated, the actions within this practice are emergent and thus dependent on a variety of inter- dependent factors that occur in the moment of knowing and of fulfilling knowing needs. From this perspective, activities and knowing always have a 'where' and a 'when'; they are always situated (Nicolini et al. 2003, p. 27).

Gherardi (2003, p. 357; 2006, p. 39) summarized the core aspects of a practice-based epistemology into knowing and knowledge as being the following: (a) Knowledge is constructed by situated practices of knowledge creation and by the use of technologies for representing and mobilizing knowledge by human and non-human agents; (b) Knowledge is an emergent process rather than a given one. It is a 'bricolage of material, mental, social and cultural resources'; (c) Knowledge is 'embedded in the world of the sensible and corporeal', meaning that knowing and knowledge are not limited to cognitive and mind aspects and (d) Adopting a practice-based approach is to go beyond dualisms (e.g. mind/body, human/ 


\section{NSBM Journal of Management}

Vol. 1, No. 2, July-December, 2015

nonhuman) and considering that 'in practicing a practice all these elements are simply present'.

Several reasons lead to the use of a practice-based perspective for this study. It can provide unique insights into designing supportive approaches for knowledge creation, communication, and use that aim at service innovation. This is because a practice-based approach enables understanding how knowledge is created, and how and why knowledge is differently needed and used. In addition, this approach enables gaining a deep understanding of how knowledge is situationally constructed, activated, transformed, mobilized and how it contributes to knowledge creation and finally innovations. Most importantly, a practice epistemology incorporates the creative and interpretative actions in which existing knowledge is needed, used, and communicated.

\section{Focusing on the actual activities of work}

As explained earlier, one important contribution to knowledge management from the practice-based perspective is the identification of a kind of knowledge that is embedded in a situated activity. Practice refers to how people actually get work done (Brown \& Duguid 2001). Practice includes the means and the ends of work, the practical wisdom people rely on, and the '...rich, socially embedded clinical know-how that encompasses perceptual skills, transitional understandings across time, and understanding of the particular in relation to the general' (Brown \& Duguid, 2001). Practice-based knowledge is produced continuously in situated action, as people draw on their physical presence in a social setting, on their cultural background and experience, and on sentient and sensory information (Orlikowski 2007). Practice-based knowledge does not exist independently of social action, and its content does not necessarily mean the same thing to all involved (Dougherty 2004).

To manage practice-based knowledge for service innovation, it is therefore necessary to focus on the actual activities of work, to enable the situated activities through which people accomplish tasks, to foster skills of knowing and to legitimate engaged participation in the practice (Barley, 2006). The skills for knowing comprise the 'artful competence' of applying the principles of the profession to unique situations, and making do with resources available (Orlikowski 2002). According to Brown and Duguid (2001), practice highlights know-how defined as the ability to put know-what into practice. 
Knowledge Management for Service Innovation: A Study of Sri Lankan Business Service Organizations

\section{Research Design}

\section{Methodology}

Ethnographic interviews (Fielding \& Fielding 1986, Fontana \& Frey 1998) were carried out with 24 senior executives in ten service firms about how they develop new services and what factors influence innovation in their organizations. Questions were considered, rephrased and analyzed so that the interviewees could discuss how they experience their work, and what kinds of things are meaningful to them. The people who were involved in new service development had functional expertise of different kinds and worked at senior levels of management. The interviews lasted from between half an hour and one hour, and were done at the interviewee's work site. Respondents were asked to describe what they knew about usage and design as they innovated, how they developed new services with specific examples and how they incorporated knowledge into their work. Top managers were asked how they supported innovation, allocated resources and developed strategies. Further, questions were raised to collect information on factors that influence service innovation at organizational and contextual levels. This interview data revealed the kinds of interactions people were engaged in, the nature of their participation in work situations and activities, what they knew about designing and using new services, how they worked across boundaries to create and share knowledge, and how their organization of work affected their ability to generate and use practice-based knowledge.

\section{Sampling}

The domain of the service sector is large, so the researcher deliberately limited sampling to five service sectors with three attributes in common: operating for 10 or more years, experiencing market and technological transformations and trying to innovate. Firms that were trying to innovate were selected because this is a study of innovation, and is not intended to capture knowledge in services that do not innovate. Within these boundaries, five types of service were sampled: finance, tourism, management consulting, IT and software, and telecommunication. Although these services have different backgrounds, the firms in each type had similar competitive and marketplace transformations, and were trying to change their services to embody the knowledge of designing and using it more fully. All were building more ongoing relationships with customers and more flexible internal innovative capabilities.

The ten firms used in the analysis are listed in Table 1. 
NSBM Journal of Management

Vol. 1, No. 2, July-December, 2015

Table 1: Organisations in the Sample

\begin{tabular}{lc}
\hline Organisations & Number of people interviewed \\
\hline Finance Services & 03 \\
FIN01 & 03 \\
FIN02 & \\
Consultancy services & 03 \\
CON01 & 02 \\
CON 02 & \\
IT and Software Developing & 02 \\
ITS01 & 02 \\
ITS02 & \\
Communication & 02 \\
COM01 & 03 \\
COM 02 & \\
Tourism & 02 \\
HOT01 & 02 \\
HOT 02 & \\
\hline
\end{tabular}

Source: Author

\section{Data Analysis}

Specific analytical steps described by Strauss (1987) as elaborated by Dougherty (2002): 'open coding' (to surface many possible categories), 'axial coding' (to hone categories and articulate properties) and 'selective coding' (to articulate a core category that integrates others into a theory) were followed. Relating to the practice-based knowledge the preliminary categories included knowledge about customers, kinds of relationships with customers, kinds of work boundaries and how they were crossed or not, and connections between designing and using. Further relating to influencing factors, preliminary categories included the kind of linkage (both internal as well as external), nature of human capital (expertise, skills, and experience), nature of service systems and processes, technological exploration, nature of the home market and the mentality of workers and customers. Many people said that innovation required different mindsets and a more holistic view of the minutiae of everyday work. 
Knowledge Management for Service Innovation: A Study of Sri Lankan Business Service Organizations

\section{Discussion and Findings}

The analysis produced three major insights. The first insight was that people generate practice-based knowledge for innovation if they collectively enact three kinds of activities in their everyday work: routinely doing their particular designing activity, participating in the whole flow of designing and using and reflecting in action. These activities constitute a common ground for social action, so people can engage in situated learning and make sense of what they learn in similar ways across the organization and use the knowledge for future innovation. An example from one of the information technology firms (ICT02) illustrates the activities of practice through which people generate knowledge for innovation. When one of the senior executives was asked how they designed a successful new service, he explained that they looked at improvisations that the operations people had already tried:

Actually it was very easy. We were already doing this on a random basis because some customers wanted this kind of service, so from time to time, we were doing it for free. We were already providing this service for a few customers .....sort of experiment.... With the knowledge coming from operations in most of my career, I find it is not hard to envision what to do and where to go... (ICT02)

When the same question was asked from a top manager of a private commercial bank (FIN01), he replied that they let the operational people from different functional areas get together to design the service, implement it and discuss the outcome after the implementation process.

Our job was to figure out how to implement new computer technology. Our method was to infiltrate the organization, not just single functions. . . We'd get people from different departments together . . . and say here is a problem that runs across the programmes and functions. . . You figure it out. Solve the problem and implement it. That was very successful ...'(FIN01)

They used their everyday practice of supplying the service to learn about new services. They drew practice-based knowledge on integrated customer issues integrated with operations issues. They also did not set and solve the problem abstractly, based on algorithms of modeling. Instead, they were deeply engaged in the firm's actual practices by working with functional managers, project managers, other operational level workers and drawing on their own experience in designing software and providing financial services. They traced out the ad hoc improvements that were made for particular customers and even experimented by adding new services and features to their services. They reached deep into the realities of 


\section{NSBM Journal of Management}

Vol. 1, No. 2, July-December, 2015

their operating system to see the interconnections among activities, and to reflect in action on how new interactions could mesh with the system.

Both examples of innovations are general solutions that are adapted to particular problems of existing services. Researchers emphasize that services are about solving customers' problems (Morris \& Empson 1998). In 2010, Hertog et al. defined service innovations as new solutions for the specific problems of customers. However, based on the findings of this study, the present researcher suggests that services are more than solutions for specific problems, and that practice in services can be defined as ongoing interactions of problem setting and problem solving and providing solutions for problems that the clients actually face. Conceptualizing practice in service innovations as an active, situated and coherent flow of problem setting and problem solving activities is a simple framework for the three activities, binding them sensibly and providing people with an image of what needs to be done.

In relation to the second insight (objective) it was found that the service organizations in which their organizing activities are centred on pre-established outcomes rather than ongoing current practices eliminates common grounds for knowledge creation, sharing and using the shared knowledge for innovation. In these organizations, the activities are separated into functional units so employees are involved in their own work without regard for how these are connected with the activities of others. These conventional approaches to organizing are 'anti practice' in two ways. First, they push the activities into the background, which eliminates the common ground for knowledge creating, sharing and replicating that the three activities provide. Second, conventional organizing de-legitimates practice by focusing attention on generic outcomes that do not frame everyday activities coherently and sensibly. People cannot articulate new ideas and combine them with old ones, so the organization cannot learn. The following three excerpts illustrate the way the traditional approaches eliminate the common ground for knowledge creation, sharing and using the knowledge for innovations.

...We recognized that we were not doing a good job ... Everyone was doing it in their own way and there was no synergy. We lost the synergy of a bigger company. We would use just a parochial approach . . . due to our cost-centred approach..(FIN02)

...This is a very traditional organization and each department has responsibility for certain areas. If you need them to do something you have to do the specs for them and hand the job over to them.'(FIN02). 
Knowledge Management for Service Innovation: A Study of Sri Lankan Business Service Organizations

For years we have been an organization with ... corporate priorities per year. A few years ago I personally was working on 5 or 6 corporate priorities. There are no resources for all this work. . The organization does prioritization without meaning.(HOT01)

The innovation-related problems of these organizations could not however be resolved by shifting around the current structure, or by adding new links or parts. The more successful reorganizations were based on very different principles of organizing. The following three examples illustrate new ways of creating knowledge for service innovation:

We no longer have a [build it?] and they will come with an attitude. We are more customer- and business problem-oriented. (HOT02)

We are changing, with more emphasis on quality and how we manage, and more elements of performance evaluation are on the outside activities (COM02)

We start with a needs assessment, a strategic analysis of the organization. We start with their (client's) strategy and see how this demand for training contributes to it. (CON02)

Further, a range of internal factors were found to be related to the knowledge management practices and innovative performance of the service firms in this study. The importance of internal linkages, structural elements, and organizational culture, poor knowledge dissemination, the availability of an expert and skilled work force, carrying out internal R\&D, technological exploration, internal systems and process stands out.

The respondents recognized the need to develop practice-based new knowledge and encourage it through internal networks:

We need to talk to one another and from that interact and we [then] create new knowledge and better ways of doing things (CON01)

However, one of the participants mentioned his experience of the lack of innovation in his organization as:

'We are not used to having discussions and letting knowledge emerge out of that. It is usually a one-way [top-down] process.(FIN02) 


\section{NSBM Journal of Management}

Vol. 1, No. 2, July-December, 2015

Another participant (COM 02) quoted his experience where a complex designing problem was solved not by technical experts or senior engineers but by bringing together a group of people who had a lot of tacit knowledge of designing. This tacit knowledge, shared through discussion and interaction, was embodied into a solution for the designing problem. Thus, through internal connections, employees at all levels can contribute to innovation through knowledge construction (Demerest 1997).

Some participants considered service innovation resulting from practice-based knowledge management as being reflected in the organization's structure. Agreeing with Handy (1984), Peters (1992) and Bessant (1996), they preferred open flat dialogue-based structures.

It's a mixture of bottom-up and top-down...you can set up depositories of knowledge which people can access...faster decision making. (COM01)

Further, the role of a supporting open and participative culture (Brand, 1998) was seen as vital for service innovation through knowledge sharing practices:

We try to limit them [employees] and hence lose a lot of knowledge.

Knowledge is power, there is also fear...it is a cultural problem.

Fear of giving up knowledge. Will it affect my usefulness?

The frustrations associated with lack of innovation because of poor knowledge dissemination were also expressed:

The information is there and available to everyone but it is not being transferred, absorbed and accepted. (FIN02)

The availability of staff with expertise and skills and the existence of different sorts of routines and norms to share knowledge were also found to make a strong impact on innovative performance.

There is internal training provided by people such as experts and specialists to newcomers and people who move to new jobs or internal job rotations. And there are innovation days and we have these days on a regular basis for people to innovate and prototype and learn new stuff and so on. There are certain days for you (employees) that are not related to project jobs. You (employees) must be here at work and do something but not project work, something else. (COM01) 
Knowledge Management for Service Innovation:

The analysis supports the findings of earlier research concerning the importance of the above factors as a means of boosting innovation.

\section{Implications}

\section{Theoretical Implications}

Large scale surveys and government-sponsored research projects relating to innovation in services were launched in the UK and other western countries (e.g., Community Innovation Survey (CIS) -UK Department of Trade and Industry.). However, further steps to theorize or generalize the findings regarding innovation in services is still in its infancy (Flikkema et al. 2007). Most of the papers titled "Innovation in Services" deal with questions of typology both for services per se and innovation in services (Bessant \& Davis 2007 as cited by Suphawan 2009).

The other line of research regarding innovation in services investigated the drivers of service innovation or service development processes. For example, Flikkma et al. (2007) emphasized changes in macroeconomics, e.g., social and technological dimensions as drivers of innovation; Fujakawa and Kay (2008) pointed out that new services are the exploitation of change in consumer life styles; Wilson (2008) as cited by Suphawan (2009) reviewed five models of new service development based on a case study of health care service providers. However, the innovation process, especially how innovation in services is created, has not been fully addressed in the world context or the Sri Lankan context. According to the available resources, the researcher is in the opinion that no research has been done in the selected area in the Sri Lankan context.

The empirical finding of this study is that three organizing principles (routinely doing their particular designing activity, participating in the whole flow of designing and using and reflecting in action) together provide a relational infrastructure through which people generate practice-based knowledge organization-wide. The findings suggest that practice-based knowledge has strategic value for service organizations because it captures the designing and using of knowledge necessary for innovation. The present study confirms that a practicebased view would add a much richer perspective that is more closely aligned to employees' actual work and it rejects the non-practice based approaches ( cognitive and structural ) to knowledge creation which are based on a rationalistic and objectivistic idea of knowledge (Gherardi2006, Patriotta 2003). Thus, this research creates a new category of knowledge in the area of study. The knowledge created through this research is an original contribution to 


\section{NSBM Journal of Management}

Vol. 1, No. 2, July-December, 2015

the existing body of knowledge. Since there are no past studies done in this area, variables that operate in this environment are not identified and documented.

\section{Implications for practice}

The strategic articulation of practice standardizes people's understanding of what we do, how and why, providing common, sensible frames for practice (Fiol 1994). The first strategy is defining each practice as a kind of problem that employees set and solve, articulates what people should do and how they should make sense of their actions. They can thus approach specific projects more systematically because they think about the overall process that produces the problem, not just the unique aspects of particular situations. The second strategy is to formally include the three activities of practice in everyone's job. Such organizing keeps everyone in the know because they can apply similar knowledge in their everyday work, which provides a common ground for knowledge creation and sharing across boundaries. The third new principle is to formally address the factors that influence practice-based knowledge management and service innovation. For example, creating strong internal networks, building open and less hierarchical structural elements and positive and open organizational cultures and hiring experts and a skilled work force can be considered as strategies which can be used to create a favorable climate for service innovation. The top management should give their fullest attention to those factors that influence service innovation at organizational level. Together, these organizing principles articulate the practices themselves and the relationships among the activities in the practices (Obsfeld 2003).

\section{Conclusion}

The creation of practice based knowledge is one of the most unstructured and difficult work practices to be facilitated and supported. It presents a particular nature and dynamics that is marked by emergent, unplanned and situational sense-making, demanding different approaches to communicate knowledge as inputs to and products of such practice. However, as organizations move further into a 'knowing economy' where knowledge creation and innovation are increasingly central to organizational effectiveness, it is necessary to pay more attention to the ways knowledge creation and use can be facilitated and supported. It is necessary to promote interactions and relationships that individuals can rely on to access each other's' personal and practice based knowledge to accomplish work activities, and mainly, to become more strategic and innovative. 
Knowledge Management for Service Innovation: A Study of Sri Lankan Business Service Organizations

This research integrates work as practice with knowledge for innovation and strategic services management. Even though it was found out that three organizing principles together provide a relational infrastructure through which people generate practice-based knowledge organization-wide, there are no simple processes. As indicated by the findings practice based knowledge is not simply about tacit knowledge, expertise or experience, but rather it is about the artful, skilled combination of these along with knowledge in routines, involvement in the whole process and reflection. Thus, research on interactions among knowledge types is necessary. For example, experience affects people's ability to comprehend insights generated in practice. It would be useful to explore the kinds of experience that may enable or disable practice-based knowledge in the business services.

Further, even though this papers has examined organizational level factors that influence knowledge management practices and service innovation, it has not examined the influence of external factors and other contingency factors have on the concepts of knowledge management and service innovation. I acknowledge that these factors are important to future research. Further work needs to be undertaken to understand how contingency factors will alter the relationships discussed in this paper, by contextualizing any future empirical work based on a contingent approach. Finally, findings of this research can be utilized for future studies by taking quantitative research method through empirical surveys.

\section{References}

Annual Report of the Monetary Board 2014, Central Bank of Sri Lanka, Sharp Graphic House (Pvt.) Ltd.

Barley, S 1996, 'Technicians in the workplace: ethnographic evidence for bringing work into organization studies', Administrative Science Quarterly, vol. 41, pp. 404-441.

Bessant J 1996, Learning networks: an introduction, Internal Report, University of Brighton.

Brand A 1998, 'Knowledge management and innovation at 3M', Journal of Knowledge Management, vol. 2, no 1, pp. 17-22.

Brown, JS \& Duguid, P 2001, 'Knowledge and organization: a social practice perspective', Organization Science, vol. 12, no.2, pp. 198-213.

Bullinger, HJ, Warnecke, HJ \& Westkamper, E 2003, Neue organisation formen in untervehmen. Berlin, Germany: Springer verlag.

Carlile, P 2002, 'A pragmatic view of knowledge and boundaries: boundary objects in new product development', Organization Science, vol. 134, no. pp. 442-55.

Consoli, D 2009, An evolutionary perspective of health innovation systems. Journal of Evolutionary Economics, vol. 19, no.2, pp. 297-319. 


\section{NSBM Journal of Management}

Vol. 1, No. 2, July-December, 2015

Consoli, D \& Elche-Hortelano D 2010, Variety in the knowledge base of business service sectors, Research Policy, vol. 39, pp. 1303-1310.

Dankbaar, B 2003, 'Towards a new paradigm? Innovation management in knowledge intensive business services', in B. Dankbaar (ed) Innovation and knowledge management, pp.343-362, Imperial College Press, London.

Damanpour, F \& Gopalakrishnan, S 2001, 'The dynamics of the adoption of product and process innovation in organizations', Journal of Management Studies, vol. 38, no.1, pp. 45-65.

Das SR \& Canel, C 2006, 'Designing service processes: a design factor based process model,' International Journal of Services Technology and Management, vol. 7, no. 1, pp. 85-107.

De Jong, J, Bruins, A, Dolfsma, W \& Meijaard, J 2003, 'Innovation in services firms explored: what, how and why?' EIM, Business and Policy Research, Zoetermeer.

Demarest, M 1997, 'Understanding knowledge management'. Manage. Commun. Q., vol. 16, pp. 374384.

Dougherty, D 1992, 'A practice-centered model of organizational renewal through product innovation', Strategic Management Journal, vol. 13, pp. 77-92.

Dougherty, D 2002 'Building grounded theory: some principles and practices', in AC Joel and DC Baum (eds) Companion to organizations, pp. 849-67, Blackwell, Oxford.

Dougherty, D 2004, 'Organizing practices in services', Journal of Strategic Organization, vol. 2, no. 1, pp. 35-64.

Dutta S 2012, Global innovation index, World Intellectual Property Organization.

Fielding, N \& Fielding, J 1986, Linking data, qualitative research methods, Series 4. Beverly Hills, CA.

Eurostat 2005, 'European system of national and regional account 2005' in the European Parlimente, http://ec.europa.eu/eurostat/statistics-explained/index.php

Fiol, CM 1994, 'Consensus, diversity, and earning in Organizations', Organization Science, vol. 53, pp. 403-21.

Flikkema, M, Jansen, P \& Van der Sluis, L 2007, 'Identifying neo-Schumpeterian innovation in service firms: a conceptual essay with a novel classification', Economics of Innovation and New Technology, vol. 16, no.7, pp. 541-558.

Fontana, A \& Frey, J 1998, 'Interviewing; the art of science', in N Denzin and Y Lincoln (eds), Collecting and Interpreting Qualitative Materials, pp. 47-78, Thousand Oaks, CA: Sage Publications.

Global Innovation Index 2013, World intellectual property organization. INSTEAD publications.

Gadrey, J, Gallouj, F, \& Weinstein, O 1995, 'New modes of innovation: how services benefits industry', International Journal of Service Industry Management, vol. 6, no.3, pp. 4-16

Gherardi, S 2003, 'Knowing as desiring: mythic knowledge and knowledge journey in communities of practitioners', Journal of Workplace Learning, vol. 15-17, pp. 352-358.

Gherardi, S 2006, Organizational knowledge: the texture of workplace learning, Blackwell Publishers, Oxford. 
Knowledge Management for Service Innovation: A Study of Sri Lankan Business Service Organizations

Gherardi, S 2009, 'Communities of practice or practices of a community?' in S Armstrong and C Fukami (eds), Handbook of management learning, education and development, pp. 514-530, SAGE, London.

Griffin, E 1997, A first look at communication theory, McGraw-Hill Companies, New York.

Gro"nroos, C 2007, Service management and marketing: a customer relationship management approach, 3rd edn, Wiley, Chichester.

Handy, C 1989, The age of unreason, HBR Press, Boston, MA

Hertog, P, van der Aa, W \& de Jong, MW 2010, 'Capabilities for managing service innovation: towards a conceptual framework'. Journal of Service Management, vol. 21 no.4, pp. 490-514.

Ianseti, M 1998, Technology integration. HBS Press, Boston, MA.

Itami, H. 1987, Mobilizing invisible assets. HBS Press, Boston, MA.

Johne, A \& Storey, C 1998, 'New service development: a review of the literature and annotated bibliography', European Journal of Marketing, vol. 32, pp. 184-251.

Kelegama, S 2013, 'Sri Lanka's lack of innovation limit export growth', paper presented at the 18th Annual General Meeting, National Chamber of Exporters of Sri Lanka

Kotler, P, Armstrong, G, Saunders, J \& Wong, V 1999, Principles of marketing, 22nd edn, Prentice Hall Inc., Upper Sadle River.

Lave. J 1988, Cognition in practice, Cambridge University Press, Cambridge, U.K.

Leonard-Barton, D 1995, Well-springs of knowledge: building and sustaining the sources of innovation, HBS Press, Boston, MA.

Lowendahl, B 2000, Strategic management of professional service firms, 2nd edn, Copenhagen Business School Press, Copenhagen.

Meffert, H and Bruhn, M 2009, Dienstleistugs marketing, 6th edn, Wiesbaden, Gabler

Miles, I 2005, 'Innovation in services', in J Fagerberg, R Mowery and R Nelson, The Oxford handbook of innovation, Oxford University Press, Oxford, pp. 433-458.

Meyer, M \& DeTore, A 2001 'Creating a platform-based approach for developing new services', Journal of Product Innovation Management, vol. 18, no. 3, pp. 188-204.

Menor, L, Tatikonda, M \& Sampson, S 2002, 'New service development: areas for exploitation and exploration', Journal of Operations Management, vol. 20, pp. 135-157.

Morris, T \& Empson, L 1998, 'Organization and expertise: an exploration of knowledge bases and the management of accounting and consulting firms', Accounting, Organizations and Society, vol. 23, no. 5/6, pp. 609-624.

Nicolini, D, Gherardi, S \& Yanow, D 2003, 'Introduction: towards a practice-based view of knowing and learning in organizations', in D Nicolini, S Gherardi \& D Yanow (eds), Knowing in organizations: a practice-based approach, pp.3-31, ME Sharpe, London.

OECD 2014, OECD Economic Outlook, vol. 2014/1, OECD Publishing, http://dx.doi.org/10.1787/ eco_outlook-v2014-1-en 


\section{NSBM Journal of Management}

Vol. 1, No. 2, July-December, 2015

Obsfeld, D 2003, 'Engineering knowledge: innovation as knowledge creation and social movement', working paper, University of California, San Francisco, CA.

Orlikowski, W 2002, 'Knowing in practice: enacting a collective capability in distributed organizing', Organization Science, vol. 13, no. 3, pp. 249-73. .

Poppelbub, J, Plaltfaut, R \& Ortback, K 2011, 'Service innovation capability: proposing a new framework,' proceedings of the Federated Conference on Computer Science \& information systems, pp. 545-551.

Quinn, JB \& Gagnon, C 1986, 'Will services follow manufacturing into decline?' Harvard Business Review, vol. 10, no. 6, pp. 95-106.

Schwab, A 2012, The global competitiveness report, World Economic Forum

Scupola, A 2003, 'Government intervention in SME'S e-commerce adoption: an institutional approach', proceedings of 7th Pacific Asia Conference on Information Systems

Spohrer, J, Vargo, SL, Caswell, N \& Maglio, PP 2008, 'The service system is the basic abstraction of service science', proceedings of the 41st Annual Hawaii International Conference on System Science, 7-10 January, Hilton Waikoloa Village Resort, Waikoloa, Big Island, Hawaii, available at: www.hicss.hawaii.edu/hicss_41/apahome41.html

Strauss, A 1987, Qualitative analysis for social scientists, Cambridge University Press. New York.

Terril, CA \& Middlebrooks, AG 1996, 'Service development', in MD Rosenale et al. (eds), The PDMA Handbook of product development, John Wiley \& Sons, New York,

Tidd, J, Bessant, J \& Pavitt, K 2005, Managing innovation: integrating technological, market and organizational change, 3rd edn, John Wiley \& Sons, New York.

Tsoukas, H \& Vladimirou, E 2001, 'What is organizational knowledge?' Journal of Management Studies, vol. 38, pp 973-93.

Teece, DJ 2007, 'Explicating dynamic capabilities: the nature and micro-foundations of sustainable enterprise performance'. Strategic Management Journal, vol. 28, no. 13, pp. 1319-1350.

Vitharana, T 2011, 'Innovation: the road overcome to poverty in Sri Lanka', press release, National Science and Technology Foundation.

Yakura, E 2001, 'The valorization of time in consulting', American Behavioral Scientist, vol. 44, no. 7, pp. 1076-1095.

Zeithaml, VA, Berry, LL \& Parasuraman, A 1990, Delivering quality service: balancing customer perceptions and expectations. Free Press, New York. 